NASA Technical Memorandum 110324

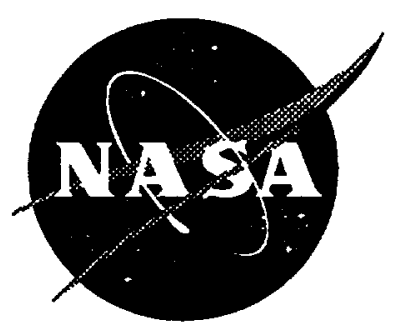

\title{
STS-74/Mir Photogrammetric Appendage Structural Dynamics Experiment Preliminary Data Analysis
}

Michael G. Gilbert, Sharon S. Welch, Richard S. Pappa, and Martha E. Demeo Langley Research Center, Hampton, Virginia

February 1997

National Aeronautics and Space Administration Langley Research Center Hampton, Virginia 23681-0001 



\title{
STS-74/MIR PHOTOGRAMMETRIC APPENDAGE STRUCTURAL DYNAMICS EXPERIMENT PRELIMINARY DATA ANALYSIS
}

\author{
Michael G. Gilbert', Sharon S. Welch ${ }^{1}$, Richard S. Pappa ${ }^{2}$, and Martha E. Demeo ${ }^{2}$ \\ NASA Langley Research Center \\ Hampton, VA 23681-0001
}

\begin{abstract}
The Photogrammetric Appendage Structural Dynamics Experiment was designed, developed, and flown to demonstrate and prove measurement of the structural vibration response of a Russian Space Station Mir solar array using photogrammetric methods. The experiment flew on the STS-74 Space Shuttle mission to $\mathrm{Mir}$ in November 1995 and obtained video imagery of solar array structural response to various excitation events. The video imagery has been digitized and triangulated to obtain response time history data at discrete points on the solar array. This data has been further processed using the Eigensystem Realization Algorithm modal identification technique to determine the natural vibration frequencies, damping, and mode shapes of the solar array. The results demonstrate that photogrammetric measurement of articulating, nonoptically targeted, flexible solar arrays and appendages is a viable, low-cost measurement option for the International Space Station.
\end{abstract}

\section{Introduction}

On-orbit structural response measurements of the International Space Station (ISS) are required for loads validation and verification of structural mathematical models. Typically, structural response time-history data would be collected with on-board sensors such as strain gages or accelerometers, signal conditioned, and transmitted (downlinked) to the ground for further processing. From the time history data, structural dynamic characteristics (structural mode frequencies, dampings, and mode shapes) would be determined using structural identification algorithms such as the Eigensystem Realization Algorithm (ERA) [1]. Accelerometer and strain gage measurements of the ISS primary truss are currently planned for loads validation and model verification; however, accelerometer or strain gage measurements of solar array response are not being considered because of the impact on cost and resources.

Photogrammetric measurement of solar array structural response is a low cost alternative to dedicated accelerometer measurements, especially when

\footnotetext{
'Senior Research Engineer, Senior Member AIAA

${ }^{2}$ Research Engineer
}

Copyright $(C) 1997$ by American Institute of Aeronautics and Astronautics. Inc. No copyright is asserted under Title 17. U.S. Code. The U.S. Government has a royalty-free license to exercise all rights under the copyright claimed herein for Governmental measurements are required for articulating or rotating spacecraft components such as solar arrays or thermal radiators $[2,3]$. Elimination of accelerometers and their associated power and data wiring, signal conditioning and digital conversion electronics, etc., can greatly simplify the spacecraft electrical design and integration and reduce spacecraft cost.

The Photogrammetric Appendage Structural Dynamics Experiment (PASDE) was developed to mitigate the technical risk and cost associated with onorbit measurement of solar array and other flexible appendage structural responses for the ISS program. The experiment objectives were to demonstrate photogrammetric structural response measurement methods for solar arrays using video cameras without the use of optical targets, to provide engineering data on solar array designs similar to those expected to be used on the ISS, and to verify that routine on-orbit spacecraft operational events provide sufficient excitation for structural response testing.

The NASA Langley Research Center (LaRC) and the NASA Goddard Space Flight Center (GSFC) were funded to conduct the PASDE experiment. PASDE flew in space on the Space Shuttle STS-74 mission in November 1995 to the Russian Mir space station as part of the ISS Phase I program. For the STS-74 mission, PASDE was manifested with the Arizona State University Glo-4 experiment as the Hitchhiker Glo-4/PASDE or GPP payload [4].

\section{Design and Development}

The objective of the PASDE experiment was to measure the response of the Mir Kvant-II module lower solar array shown in Figure 1. During the docked portions of the mission, this array was outboard of the Shuttle on the port side, slightly ahead of the wing. Based on the length of the Kvant-II solar array and possible viewing geometries, a PASDE design using six video cameras and recorders in three Hitchhiker canisters located in the Shuttle payload bay was selected. In this design, one camera in each canister is aimed and focused at the root of the array, and the other at the tip to provide full video coverage and optimize to the extent possible the triangulation geometry. Each video recorders could record 120 minutes of video data. 
Three sets of identical flight hardware were fabricated, assembled, and tested at the NASA Langley Research Center beginning in October 1994. Each PASDE flight unit was integrated with a Hitchhiker canister at GSFC and the integrated Hitchhiker hardware was delivered to the NASA Kennedy Space Center (KSC) in July 1995. At KSC a pre-flight photogrammetric calibration of the hardware and ground simulation of the experiment was performed using a simulated solar array assembly. Results from this preflight ground experiment are documented in [5].

The three Hitchhiker canisters containing the PASDE flight hardware were mounted aft of the expected Kvant-II array position in Space Shuttle Atlantis payload Bay 6 (port side), Bay 7 (starboard side), and Bay 13 (port side) following the pre-flight calibration and testing. Additional information on PASDE design requirements and hardware are described in [6].

\section{Mission Operations}

STS-74 launched at 7:30:43 am EST on November 11, 1995. PASDE mission operations were conducted during the STS-74 mission from the Hitchhiker Payload Operations Control Center (POCC) at NASA GSFC. The PASDE hardware was commanded from the POCC by Hitchhiker personnel under the direction of the PASDE operations team. Table 1 summarizes actual PASDE operations during the mission. Events are listed with reference to Mission-Elapsed-Time (MET) in day:hours:minutes format, amount of data recorded in minutes:seconds format, and a short description. Additional details regarding the on-orbit operations of PASDE can be found in [6].

\section{Post-Flight Calibration and Flight Data Retrieval}

The PASDE hardware underwent post-flight photogrammetric calibration following removal from the Shuttle using the same procedures and simulated solar array as were used in the pre-flight calibration. The post-flight calibration data was recorded directly on the flight data tapes and used for subsequent photogrammetric data analysis processing. Upon return of the hardware to LaRC, the PASDE data tapes were removed from the flight video recorders and duplicated. Five of the six camera/recorder combinations performed as designed, providing excellent quality video imagery of solar array motions. The Bay 7 Tip camera exhibited intermittant anomalous behavior, resulting in some data loss (estimated at $50 \%$ ) for that camera/recorder combination.
Data Processing Methods

The process of extracting the structural dynamic characteristics of mode frequencies, dampings, and mode shapes from the recorded video images is described below. The basic outline of the process is a) digitization (conversion) of the analog video data to digital form, b) identification and tracking of identifiable features in the digitized images for a single camera, in camera focal plane $x-y$ pixel coordinates using linetracking or scene correlation algorithms, c) triangulation of results for points coincident in 2 or more digital image sequences to physical (3-axis) coordinates, and d) application of the Eigensystem Realization Algorithm to the time history data in physical coordinates to determine modal characteristics.

Digitization - The video flight data was digitized using the hardware arrangement illustrated in Figure 2. Table 2 summarizes the data which has been digitized to date. The real-time video data rate was 30 frames per second. However, since the highest mode of interest is on the order of $0.5 \mathrm{~Hz}$, a sampling rate of $10 \mathrm{fps}$ was sufficient to characterize the motion of the array. Therefore, only every third frame of video data was saved for further processing. Figure 3 shows digitized images from five of the six PASDE cameras for the PRCS \#3, Firing \#2 data case (Note: usable data was not obtained from the Bay 7 Tip camera during this test due to the anomalous behavior previously mentioned).

Line Tracking - In the absence of optical targets, naturally occurring lines and features in the digitized images may be tracked with respect to their $x$ and $y$ pixel locations using the method of line tracking described in [7]. As shown in Figure 4, two lines delineating a target of interest may be selected by a 2 pairs of points. From the calculated slope and intercept of each line, their intersection point may be computed. This is the initial target position for the tracking algorithm. For subsequent images in a specified sequence, the tracking algorithm scans along each of the lines to find the peak pixel location (maximum intensity value) within a specified pixel width. The centroid of each scan is found, a straight line fit of the centroid values along each line is then made, and a new intersection point is computed. The $\mathrm{x}$ and $\mathrm{y}$ pixel time histories of the motion of an identified target are thereby generated for the sequence of images.

Cross-Correlation Analysis - Correlation of images allows matching of particular features in two or more separate views [8]. The cross-correlation function measures the degree of similarity of two images at various amounts of shifting of one image relative to the other. Maximum correlation occurs at the $x-y$ shift values where the two images are most similar. By 
finding the point of maximum correlation, the change of position of a "target" (i.e., any identifiable feature) from one image to the other is determined. Applying this fact to a sequence of images generates a time history of the motion.

Referring to Figure 5, the cross-correlation function of subimages $A$ and $B$ is calculated by shifting subimage $A$ over the range of $\pm M$ pixels in the $x$ direction and $\pm \mathrm{N}$ pixels in the $\mathrm{y}$ direction from its center position. Subimage A (extracted from the overall measured image) is sized to contain characteristic contrast patterns in both the $\mathrm{x}$ and $\mathrm{y}$ directions centered on the "target" of interest. The shift values $-\mathbf{M} \leq m \leq$ $\mathrm{M}$ and $-\mathrm{N} \leq n \leq \mathrm{N}$ must be somewhat larger than the distance that the target has moved from subimage $A$ to subimage $B$. In the PASDE data analysis, a typical size of subimage $A$ is 41 rows $\times 41$ columns (from a total image of 480 rows $x 512$ columns), and a typical size of $\mathrm{M}$ and $\mathrm{N}$ is 4 .

In practice, cross-correlation calculations occur in one of two ways: 1) correlation of a fixed video frame with a sequence of succeeding frames, or 2) correlation of adjacent pairs of frames with summation of the total amount of shift. The first approach is computationally simpler but does not account for rotation or scale change of the image versus time. It is applicable for most vibration problems where motion oscillates about a static position of the structure. The second approach allows general tracking of motion and is applicable for problems with large changes of orientation such as solar array slewing.

Figure 6 shows a typical cross-correlation function. Note that the basic correlation function, has a spatial resolution of 1 pixel. However the correlation function itself inherently has much higher resolution if other pixels in the neighborhood of the pixel of maximum intensity are considered. It is important in precision photogrammetry to interpolate the correlation function to subpixel resolution in order to locate as precisely as possible the position of maximum correlation [9]. The ' $x$ ' in Figure 6 shows an interpolated position of maximum correlation for the typical case. The contour lines in Figure 6 show the general shape of the correlation surface but are not used directly in the interpolation calculations.

Comparison of Target Tracking Methods - Both the cross-correlation and the line tracking method were applied to a target on the panel of the Kvant-II array as viewed from the Bay 13 Tip camera. Pixel time histories generated by each method are shown in Figure 7. In this case, and in similar cases where there is a high amount of contrast in the image, the results from the two methods are very comparable. The slight difference in mean y pixel position is attributed to the fact that the initial targets were slightly mismatched. The frequency and trends in the time histories are in good agreement.

Triangulation - The pixel time histories generated by the tracking procedures for identified targets in two or more cameras are triangulated to produce three-axis displacement of the target in the OSR coordinate system. The pixels are first mapped to inches in the image space coordinate system. These image space coordinates are then related to the object space coordinate system (OSR in this case) via the photogrammetric collinearity equations [3]:

$$
\left[\begin{array}{c}
x-x_{o} \\
y-y_{o} \\
-c
\end{array}\right]=k \mathbf{M}\left[\begin{array}{c}
X-X_{c} \\
Y-Y_{c} \\
Z-Z_{c}
\end{array}\right]
$$

where $x$ and $y$ are the coordinates of the image point, $x_{0}$ and $y_{0}$ are the coordinates of the principal point, $c$ is the principal distance of the lens, $X, Y$, and $Z$ are the coordinates of the points in the object space coordinate system, $X_{c}, Y_{c}$, and $Z_{c}$ are the coordinates of the perspective center, $\mathrm{k}$ is a scale factor ( $=1.0$ here), and $\mathbf{M}$ is a $3 \times 3$ orthogonal rotation matrix the elements $m_{i j}$ of which are the cosines of the angles between image and object space coordinate systems.

Determination of the (exterior and interior orientation) parameters of the collinearity equations was from the pre- and post-flight ground calibration data using the method of least squares. Using the computed camera parameters, triangulation of the time histories of targeted points from various camera views was accomplished. Defining

$x^{\prime}=\frac{\left(x-x_{o}\right)}{c}$ and $y^{\prime}=\frac{\left(y-y_{o}\right)}{c}$

Equation (1) was rewritten for camera $i$ as

$$
\mathbf{B}_{i} \mathbf{d}=\mathbf{B}_{i} \mathbf{d}_{i}^{\prime}
$$

where

$$
\begin{aligned}
& \mathbf{B}_{i}=\left[\begin{array}{lll}
\left(m_{11}+x^{\prime} m_{31}\right) & \left(m_{12}+x^{\prime} m_{32}\right) & \left(m_{13}+x^{\prime} m_{33}\right) \\
\left(m_{21}+y^{\prime} m_{31}\right) & \left(m_{22}+y^{\prime} m_{32}\right) & \left(m_{23}+y^{\prime} m_{33}\right)
\end{array}\right] \\
& \mathbf{d}=\left[\begin{array}{l}
X \\
Y \\
Z
\end{array}\right] \\
& \text { and }
\end{aligned}
$$




$$
\mathbf{d}_{i}^{\prime}=\left[\begin{array}{l}
X_{c} \\
Y_{c} \\
Z_{c}
\end{array}\right]
$$

For a target viewed from $l$ cameras, the vector of object space coordinates was computed by:

$\mathbf{d}=\mathbf{N}^{-1} \mathbf{t}$

where

$\mathbf{N}=\sum_{i=1}^{l} \mathbf{B}_{i}^{\prime} \mathbf{B}_{i}$ and $\mathbf{t}=\sum_{i=1}^{l} \mathbf{B}_{i}^{\prime} \mathbf{B}_{i} \mathbf{d}_{i}^{\prime}$

Modal Identification - The objective of modal identification is to decompose measured free-decay time histories into their constituent structural modal components. Each mode can be characterized by three parameters: natural frequency, damping, and mode shape. The natural frequency and damping are scalar quantities, whereas the mode shape is a complex-valued vector of $n$ components, where $n$ is the number of discrete measurement points. The Eigensystem Realization Algorithm (ERA) [1] was used for PASDE modal identification.

ERA analysis assumes that each of the measurements is the free-decay vibration response at some point on a linear, multiple-degree-of-freedom system. Using digitized samples of time histories obtained as described in sections above, $x(j), j=1,2,3, \ldots$ ERA calculates the unknown parameters in the following characteristic equation:

$$
x_{i}(t)=\sum_{r=1}^{M} A_{i r} e^{\sigma_{r} t} \sin \left(\omega_{r} t+\phi_{i r}\right)
$$

where the unknown parameters are: $M$, the number of excited modes, $A_{i r}$, the initial amplitude of mode $r$ at measurement location $i, \phi_{i r}$, the initial phase angle of mode $r$ at measurement location $i, \omega_{r}$, the frequency of mode $r$, and $\sigma_{r}$, the damping of mode $r$.

With experimental data, the number of modes $M$ is often ambiguous due to "real world" effects such as nonlinearities, noise, distortion, etc. Such ambiguity can cause significant fluctuations in some identification results. With experimental data the characteristic equation given above is not satisfied exactly for any set of parameters, and the best approximation (in a linear, least-squares sense) is used. When data for multiple measurements (and/or tests) are analyzed simultaneously, a single value of natural frequency and damping is obtained by ERA for each mode. Because natural frequencies and damping theoretically are global quantities (i.e., identical at all measurement locations and in all tests of the same structure), simultaneous analysis of multiple measurements often provides better ERA results than analysis of individual measurements.

\section{Results}

PRCS Test \#3. Firing \#2 - Structural dynamic characterization (determination of structural mode frequencies, dampings, and mode shapes) has been completed for the PRCS Test \#3, Firing \#2 (see Table 1). Figure 3 shows 12 locations on the Kvant-II solar array selected for response time history calculations. The locations are equally spaced in 2 columns on either side of the centerline of the solar array. Location Nos. 1 through 8 appear in all 3 sets of root camera video recordings. Location Nos. 9 through 12 , however, appear in only 2 of the 3 sets of tip camera video recordings due to the data loss with the Bay 7 Tip camera previously noted. The motion at each location was determined using correlation analysis method, also as described previously.

Figure 8 shows selected time history data obtained from the correlation tracking method from 4 of the twelve points identified in Figure 3 (points 4, 8, 10, and 12). The time histories are the final results of the photogrammetric analysis (triangulation) presented in 3dimensional Orbiter Structural Reference (OSR) frame coordinates. The data are arranged in 4 rows by 3 columns corresponding to the 4 measurement locations and the $\mathrm{x}, \mathrm{y}$, and $\mathrm{z}$ positions in the OSR. These data are of high quality considering the small amount of motion occurring in this test (a maximum of 1 inch peak-to-peak). The largest motions occur in the $x$ directions and these data appear as classical free-decay vibrations over the majority of the time interval. There are some unexplained fluctuations and apparent drifting in the data. The most likely source of these deviations from classical free-decay vibration is friction (stiction) and/or freeplay in the mechanisms of the Shuttle-Mir mated configuration (including the Shuttle-to-Mir docking mechanism, the rotary drive of the solar array, and the hinges and motors used to unfold the solar array from its stowed position). The time histories for locations 4 and 8 are 140 seconds in length whereas those for Locations 10 and 12 are only 60 seconds in length.

Five dominant modes were identified using ERA from the twelve points shown in Figure 3. Based on the computed mode shapes, shown in Figure 9, two of the identified modes were system modes of the mated Shuttle-Mir configuration, whereas the other three identified modes were flexible modes of the solar array. The two system modes have the following common characteristics: a) the largest motion appears at the root of the solar array rather than the tip, b) the direction of 
motion is predominantly in the $\mathrm{x}$ direction (OSR) rather than in the solar array out-of-plane or in-plane directions (the solar array out-of-plane direction is rotated 25 degrees from the OSR $\mathrm{x}$ axis), and c) the damping level is relatively high (23.7\% for system mode 1 and $3.4 \%$ for system mode 2). Common characteristics of the 3 solar array modes are: a) the largest motion appears at the tip of the solar array, b) the direction of motion is predominantly in the solar array out-of-plane ( 2 modes) or in-plane direction ( 1 mode), and c) the damping level is generally lower ( $2.4 \%$ for the first out-of-plane mode, $1.7 \%$ for second out-of-plane mode, and 3.7 for the inplane mode).

Because basic ERA analysis is a linear modal identification technique, the results shown provide a good linear representation of the solar array structural dynamics. However, significant nonlinearities were also observed in this set of PASDE data. The nonlinear effects were characterized using a sliding time-window analysis (i.e., a piecewise linear analysis) within ERA. For a linear system, natural frequencies and damping factors are constant as a function of the time shift within the sliding time-window analysis. Various types of structural nonlinearities, on the other hand, produce various changes in frequency and damping as a function of time shift.

The results of the sliding time-window analysis show that the frequency and damping are relatively constant for the first two solar array modes, while large fluctuations occur in the results for the first system mode. The first system mode probably involves the massive Mir structure flexing relative to the massive Shuttle structure through the flexibility (and damping) of the docking interface. This interface contains several mechanisms which account for the large observed damping and nonlinearity. Changes with time shift also occur for the other two solar array modes, indicative of appreciable nonlinearity, primarily in damping (perhaps energy exchange between modes).

Table 3 further summarizes the modal identification results. The range of frequency and damping values are the maximum and minimum values observed in the sliding time-window analysis. The final 2 columns in Table 3 show the physical displacement amplitude of each mode. Both the maximum initial zero-peak amplitude and the root-mean-square (rms) amplitude in the data-analysis interval are reported.

Night/Day Terminator - The orbital night/day and day/night terminator crossings of the docked Shuttle/Mir spacecraft were of interest in PASDE because of potential thermally-induced structural responses of the solar array. Time history response analysis of the night/day terminator test (see Table 1) has been completed. Three-axis triangulated data for a point near the tip of the array (approximately location 12 in Figure 3) is shown in Figure 10. Over a period of about 3 minutes following the entry of the combined Shuttle/Mir spacecraft into sunlight from darkness, the tip of the array moves quasi-statically about 0.6 inches in the $\mathbf{x}$-axis direction combined with an approximately \pm 0.05 inch, $0.16 \mathrm{~Hz}$ oscillation. Additional analysis of data for points closer to the root of the array is needed to determine if the measured quasi-static response is limited to the array only, or is the response of the combined Shuttle/Mir spacecraft to thermal loading.

Solar Array Slew - The solar array sun track rotations of the Kvant-II solar array were also considered to be a potential source of structural excitation because, unlike many U.S. systems, the Mir arrays track the sun in approximately 22 degree increments at relatively high rotational rates. Time history analysis of data for this test (see Table 1) is shown in Figure 11 ( $x$ and $y$ axis results only). The triangulated results are for a point near the root of the solar array (approximately location 2 in Figure 3). A solar array axial rotation angle (slew angle) has been computed from the data and is very close to the expected 22 degrees of rotation. Visible in the data during the slew is an $0.16-0.17 \mathrm{~Hz}$ oscillation corresponding to an excited structural mode.

\section{Concluding Remarks}

The Photogrammetric Appendage Structural Dynamics Experiment was flown on the Space Shuttle STS-74 Mission to the Russian Space Station Mir. A total of 113 minutes of video imagery of the Mir Kvant-II solar responding to various excitations was recorded. The data has been digitized, converted to threeaxis time histories for various discrete points on the solar array, and analyzed using the Eigensystem Realization Algorithm to determine structural mode characteristics. Five structural modes were identified, two combined Shuttle/Mir modes, and three Kvant-II solar array modes. In addition, the response of the array to thermal loadings from night-to-day orbital transitions and solar array sun track slewing has been determined. The experiment demonstrated that low-cost, passive photogrammetric measurement of flexible solar array and appendage structural response is feasible for use on the International Space Station.

\section{Acknowledgments}

The PASDE flight experiment involved the dedicated efforts of many individuals and teams. In particular, the efforts of the Langley Project Manager Mr. John Fedors, the PASDE Instrument team, the PASDE Mission Operations team, the GSFC POCC 
Operations team, and the Goddard GPP Mission Manager Mr. Gerry Daelemans are gratefully acknowledged.

\section{References}

[1] Pappa, R. S., "Eigensystem Realization Algorithm User's Guide for VAX/VMS Computers," NASA TM 109066, May 1994.

[2] Slama, C. C., Theurer, C., and Henriksen, S. W., Manual of Photogrammetry, Fourth Edition, Published by American Society of Photogrammetry, Falls Church, VA, 1980.

[3] McGlone, J. C., "Analytical Data-Reduction Schemes in Non-Topographic Photogrammetry," Non-Topographic Photogrammetry, Second Edition, American Society for Photogrammetry and Remote Sensing, Falls Church, VA, 1989, pp. $37-$ 57.

[4] "Glo Experiment/Photogrammetric Appendage Structural Dynamics Experiment Payload, Payload Integration Plan (PIP) Basic," NASA Johnson Space Center Document NSTS 21316, February 1995.
[5] Pappa, R. S., Gilbert, M. G., and Welch, S. S., "Simulation of the Photogrammetric Appendage Structural Dynamics Experiment," 14th International Modal Analysis Conference, Dearborn, MI, Feb. 12-15, 1996.

[6] Gilbert, M. G. and Weich, S. S., "STS-74/Mir Photogrammetric Appendage Structural Dynamics Experiment," $37^{\text {th }}$ AIAA/ASME/ASCE/AHS/ASC Structures, Structural Dynamics, and Materials Conference, Salt Lake City, UT, April 15-17, 1996.

[7] Welch, S. S., "Design and Performance of an Optical Measurement System for Position Measurement and Control in a Large Gap Magnetic Suspension System," SPIE Vol. 2350, Videometrics III, 1994, pp. 115-126.

[8] Gonzalez, R. C. and Wintz, P., Digital Image Processing, Second Edition, Addison-Wesley Publishing Co., Reading, MA, 1987.

[9] West, G. A. W. and Clarke, T. A., "A Survey and Examination of Subpixel Measurement Techniques," Proceedings of the Society of PhotoOptical Instrumentation Engineers, Vol. 1395, Sept. 1990 , pp. $456-463$

Table 1 - STS - 74 Mission Events

\begin{tabular}{|c||c||l|}
\hline $\begin{array}{c}\text { MET Ref. } \\
\text { (d:hh:mm) }\end{array}$ & $\begin{array}{c}\text { Record Time } \\
\text { (mm:ss) }\end{array}$ & \multicolumn{1}{|c|}{ Description } \\
\hline \hline $0: 00: 00$ & $00: 00$ & STS-74 launch at 7:30:43am EST, 11/12/95 \\
\hline $0: 03: 25$ & $00: 00$ & PASDE activation by Shuttle crew \\
\hline $1: 04: 45$ & $11: 35$ & Camera alignment verification and contingency data collection \\
\hline $2: 17: 52$ & $10: 47$ & Shuttle docking with Mir \\
\hline $2: 19: 22$ & $18: 34$ & PRCS Test \#1 \\
\hline $3: 16: 54$ & $09: 30$ & PRCS Test \#2 \\
\hline $4: 21: 28$ & $02: 00$ & Day-to-night terminator (Bay 6 canister only) \\
\hline $4: 21: 54$ & $05: 14$ & Night-to-day terminator \\
\hline $5: 00: 35$ & $10: 30$ & Shuttle/Mir attitude maneuver using Shuttle primary jets \\
\hline $5: 01: 43$ & $21: 50$ & PRCS Test \#3 \\
\hline $5: 06: 15$ & $01: 20$ & Solar array sun track slew maneuver \#1 \\
\hline $5: 06: 24$ & $08: 35$ & Solar array sun track slew maneuver \#2 \\
\hline- & $13: 31$ & Other data tape recording (recorder/commanding tests, etc.) \\
\hline & $113: 26$ & Total on-orbit record time (115 minutes available) \\
\hline \hline
\end{tabular}


Table 2 - Digitized PASDE Flight Data Summary

\begin{tabular}{|c||c|c|c|c|c|}
\hline Event & MET start & MET stop & Rate (fps) & \# Cameras & Total \# Images \\
\hline \hline Night/Day Terminator & $004 / 21: 56: 30.02$ & $004 / 21: 59: 30.02$ & 10 & 6 & 10,800 \\
\hline PRCS \#3 & $005 / 01: 54: 00.02$ & $005 / 01: 56: 20.29$ & 10 & 5 & 9,050 \\
Firing \#2 & & & & 5 & 3,000 \\
\hline $\begin{array}{c}\text { PRCS \#3 } \\
\text { Firing \#3 }\end{array}$ & $005 / 01: 57: 30.02$ & $005 / 01: 58: 30.02$ & 10 & 5 & \\
\hline Solar Array Slew & $005 / 06: 34: 50.02$ & $005 / 06: 25: 30.02$ & 10 & 6 & 2,400 \\
\hline & & & & & 25,250 \\
\hline
\end{tabular}

Table 3 - ERA Modal Identification Results, Test PRCS \#3, Firing \#2

\begin{tabular}{|c|c|c|c|c|c|c|c|}
\hline Mode & Description & $\begin{array}{c}\text { Nominal } \\
\text { Frequency, } \mathrm{Hz}\end{array}$ & $\begin{array}{l}\text { Nominal } \\
\text { Damping } \\
\text { Factor, \% }\end{array}$ & $\begin{array}{c}\text { Max. Initial } \\
\text { 0-Pk } \\
\text { Amplitude, in }\end{array}$ & $\begin{array}{c}\text { RMS } \\
\text { Amplitude } \\
\text { in Analysis } \\
\text { Window, in }\end{array}$ & $\begin{array}{c}\text { Frequency } \\
\text { Variation in } \\
\text { Sliding } \\
\text { Window } \\
\text { Analysis, } \\
\mathrm{Hz}\end{array}$ & $\begin{array}{c}\text { Damping } \\
\text { Variation in } \\
\text { Sliding } \\
\text { Window } \\
\text { Analysis, } \\
\%\end{array}$ \\
\hline 1 & System Mode & 0.164 & 23.7 & $\begin{array}{c}0.925 \\
\text { (Location 1X) }\end{array}$ & 0.045 & $\begin{array}{c}0.164 \\
- \\
0.210 \\
\end{array}$ & $\begin{array}{c}19 \\
- \\
37\end{array}$ \\
\hline 2 & $\begin{array}{c}\text { Solar Array } \\
\text { Out-of-Plane } \\
\text { Bending }\end{array}$ & 0.176 & 2.4 & $\begin{array}{c}0.373 \\
\text { (Location } \\
12 \mathrm{X} \text { ) } \\
\end{array}$ & 0.064 & $\begin{array}{c}0.175 \\
- \\
0.178 \\
\end{array}$ & $\begin{array}{c}0.8 \\
- \\
2.6 \\
\end{array}$ \\
\hline 3 & $\begin{array}{c}\text { Solar Array } \\
\text { Out-of-Plane } \\
\text { Bending } \\
\end{array}$ & 0.193 & 1.7 & $\begin{array}{c}0.331 \\
\text { (Location } \\
11 \mathrm{X} \text { ) } \\
\end{array}$ & 0.077 & $\begin{array}{c}0.193 \\
- \\
0.201 \\
\end{array}$ & $\begin{array}{c}1.4 \\
- \\
3.6 \\
\end{array}$ \\
\hline 4 & System Mode & 0.269 & 3.4 & $\begin{array}{c}0.090 \\
\text { (Location 2X) }\end{array}$ & 0.015 & $\begin{array}{c}0.269 \\
- \\
0.278 \\
\end{array}$ & $\begin{array}{c}0.9 \\
- \\
5.0 \\
\end{array}$ \\
\hline 5 & $\begin{array}{c}\text { Solar Array } \\
\text { In-Plane } \\
\text { Bending }\end{array}$ & 0.478 & 3.7 & $\begin{array}{c}0.153 \\
\text { (Location } \\
12 \mathrm{Y} \text { ) } \\
\end{array}$ & 0.012 & $\begin{array}{c}0.475 \\
- \\
0.483 \\
\end{array}$ & $\begin{array}{c}2.7 \\
- \\
4.4\end{array}$ \\
\hline
\end{tabular}

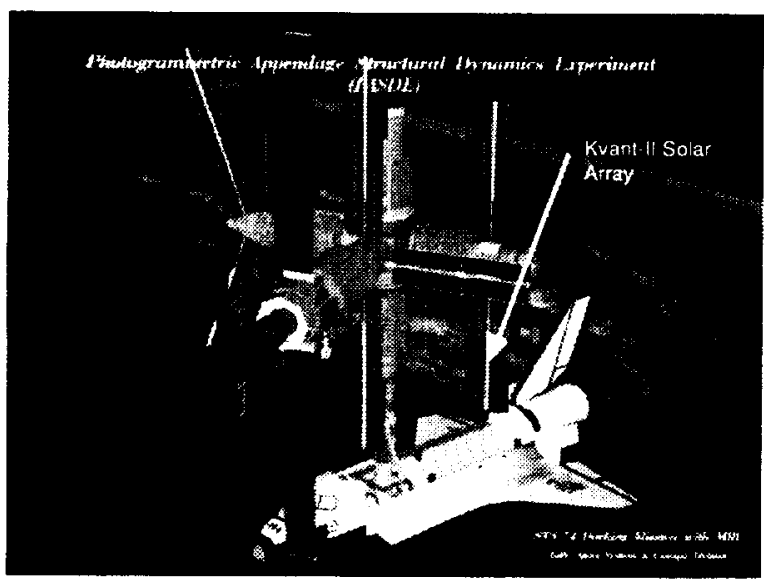

Figure 1 - STS-74 Shuttle/Mir configuration

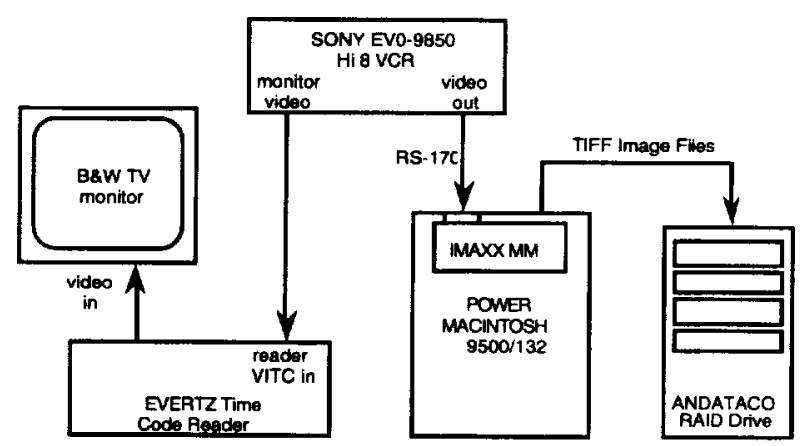

Figure 2 - Digitization Layout 

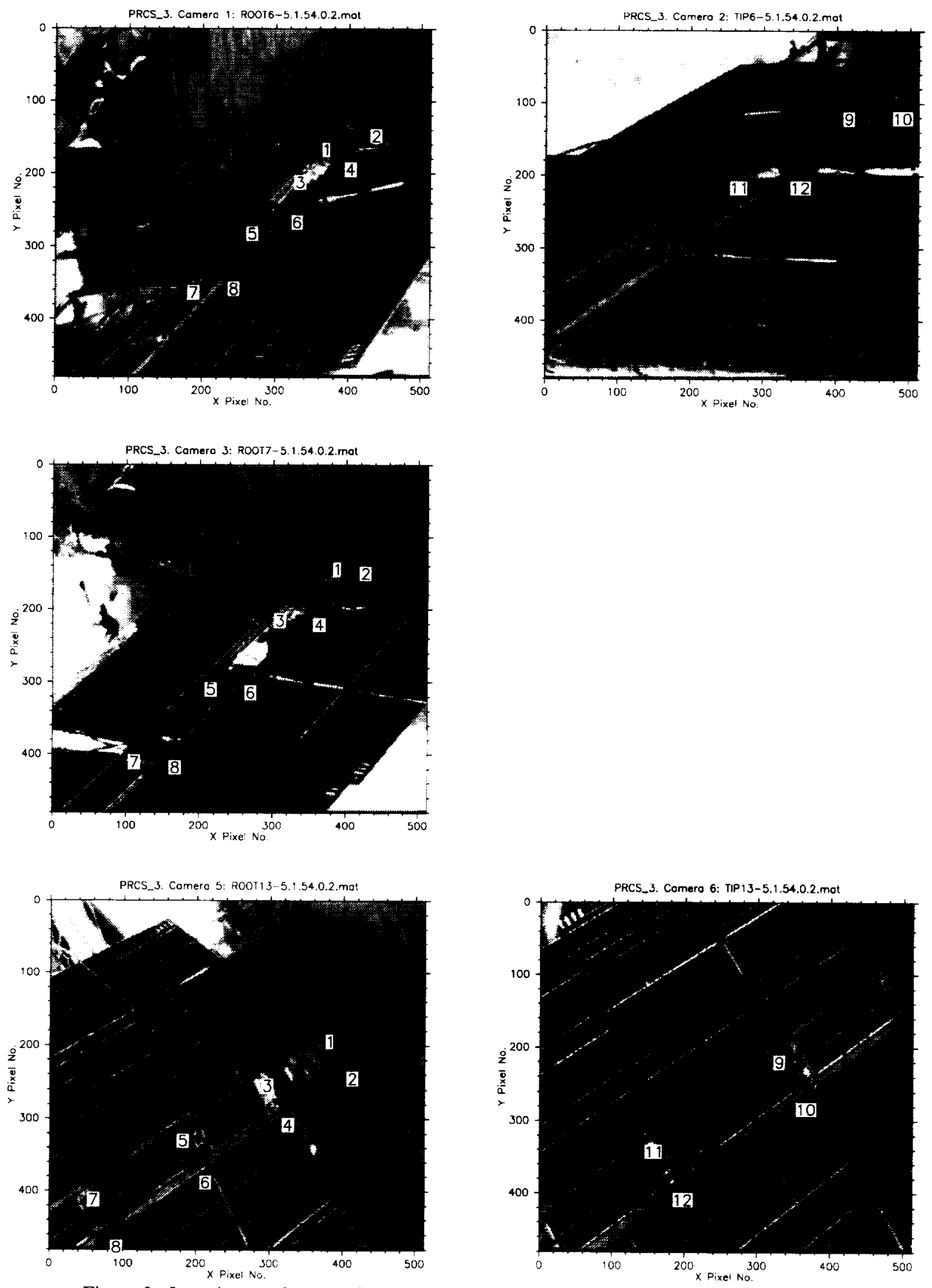

Figure 3 - Locations on Kvant-2 Solar Array Centerbox Tracked With Correlation Analysis, Test PRCS \#3, Firing \#2 (+ Pitch) 


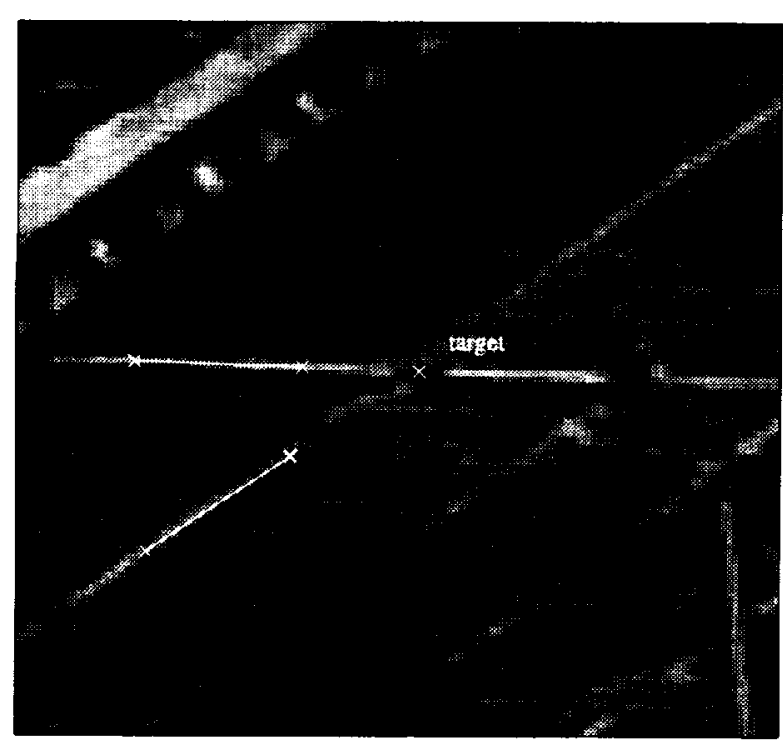

Figure 4 - (Line Track Method)

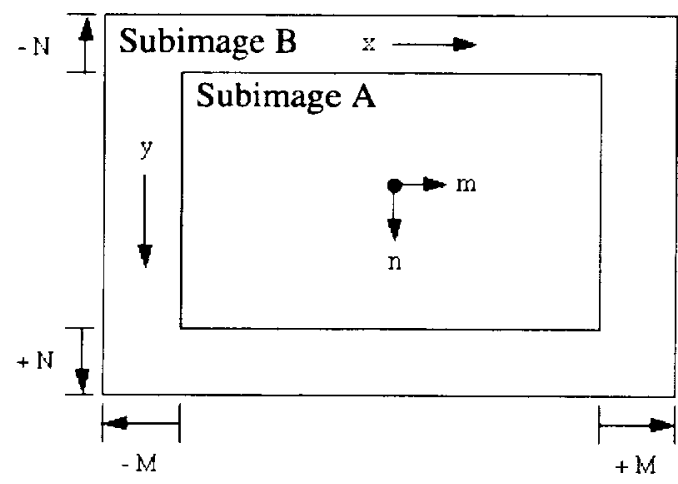

Figure 5 - Correlation of Subimages A and B

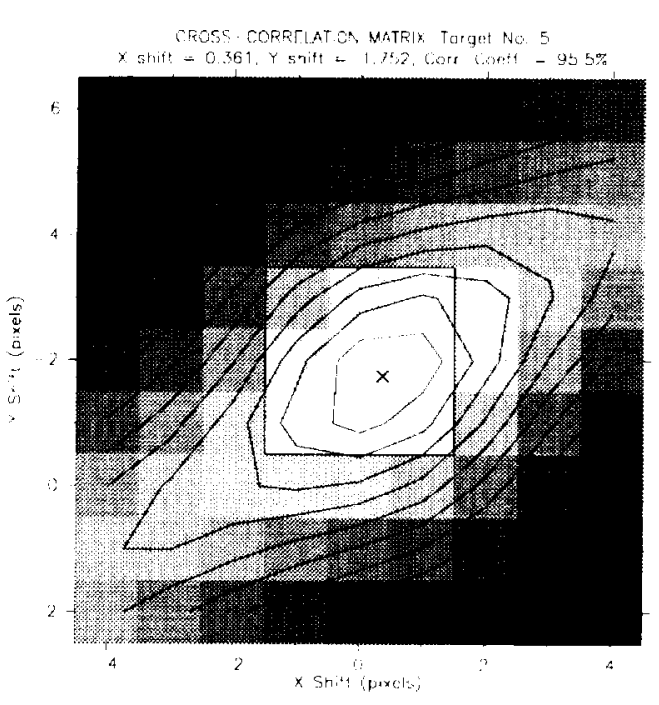

Figure 6 - Typical Cross-Correlation Function

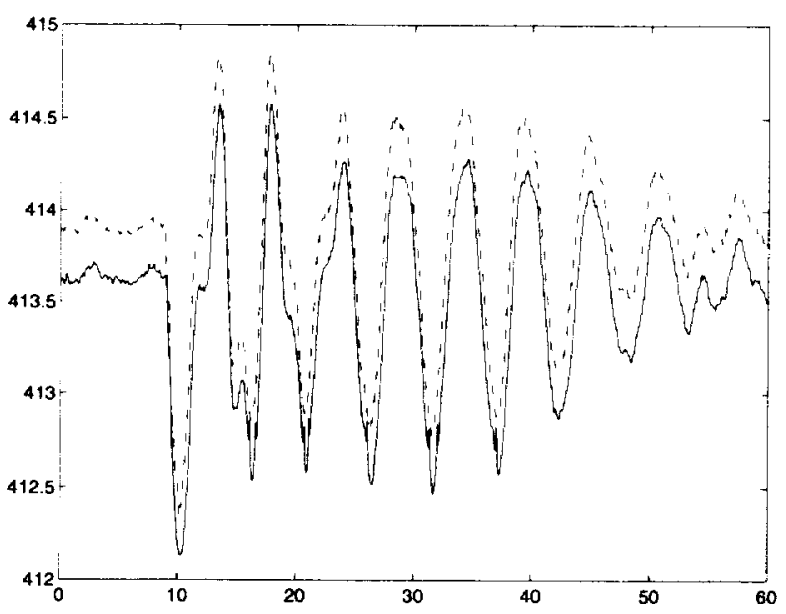

Figure 7 - Comparison of Line Track (Solid) \& Correlation Methods (Dash) 

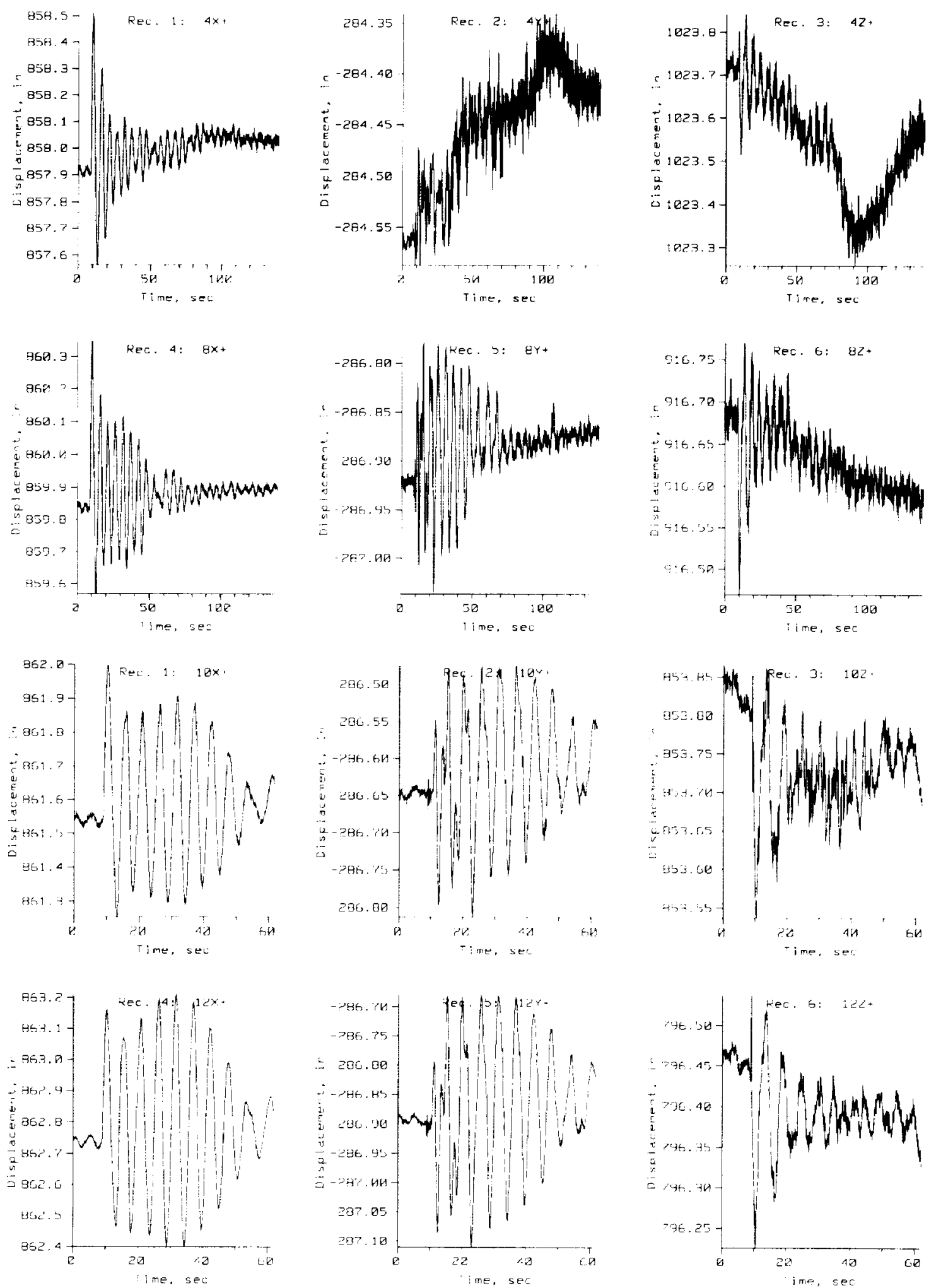

Figure 8 - Displacements in Shuttle Coordinates at Locations 4, 8, 10, and 12 on Kvant-2 Solar Array Centerbox, Test PRCS \#3, Firing \#2 (+ Pitch) 


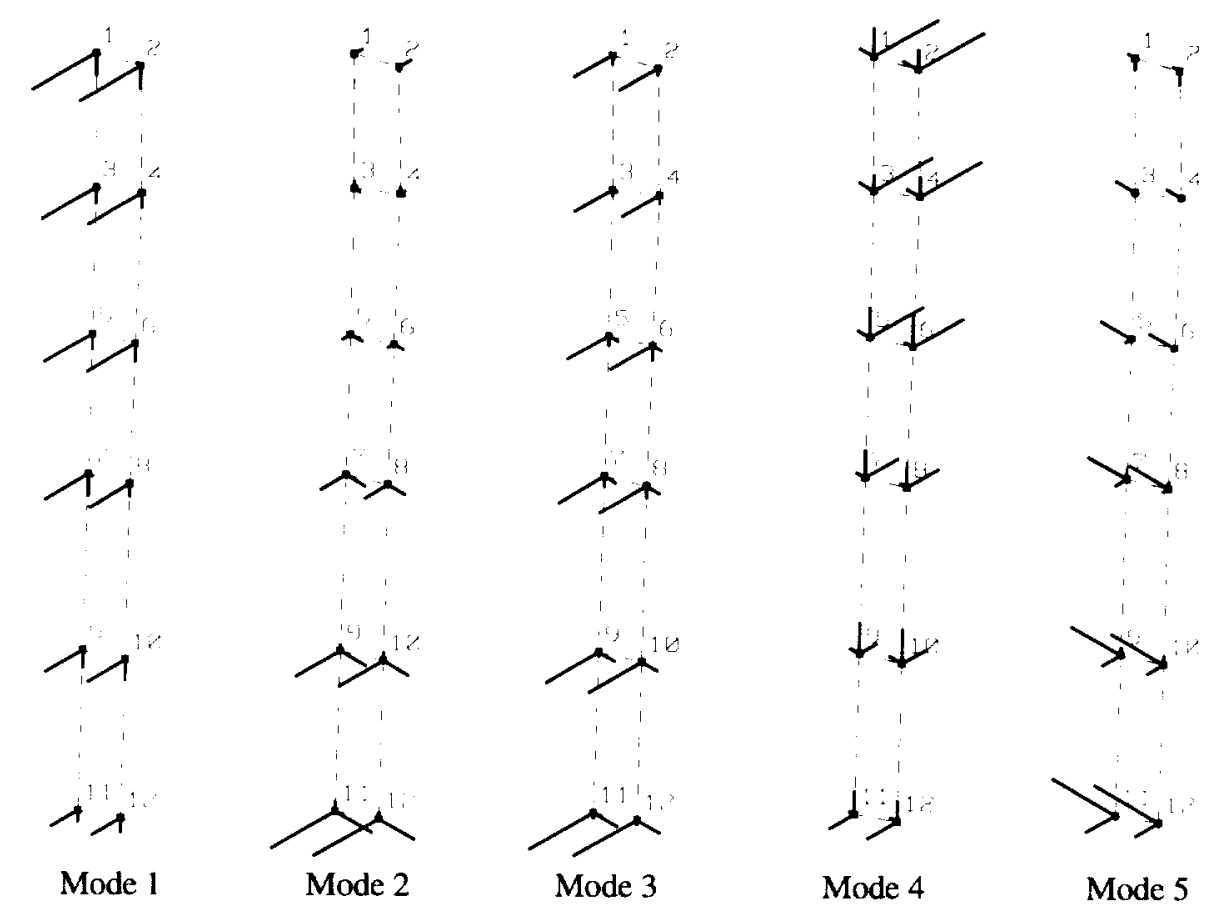

Figure 9 - Identified Mode Shapes, Test PRCS \#3, Firing \#2 (+ Pitch)
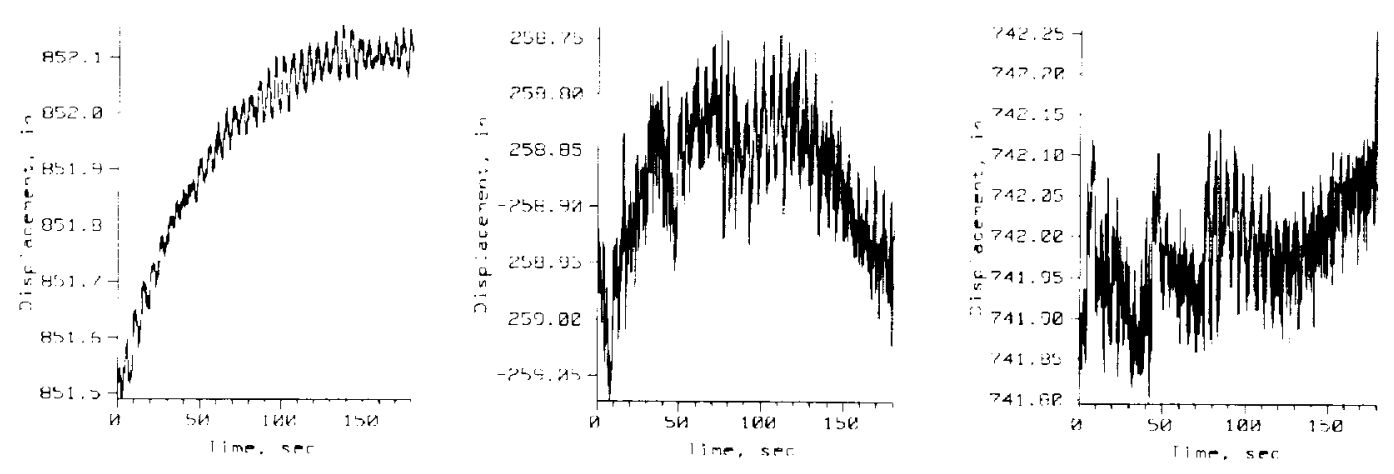

Figure 10 - Displacements in Shuttle Coordinates Near Solar Array Tip, Night/Day Terminator Test
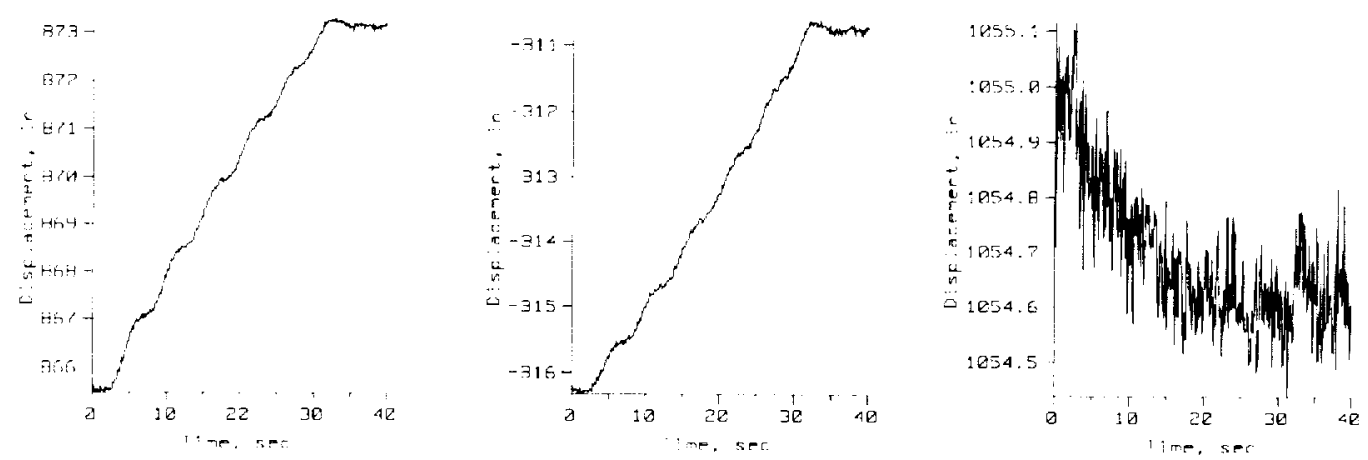

Figure 11 - Displacements in Shuttle Coordinates Near Solar Array Tip, Solar Array Slew Test 
Public reporting burden for this collection of information is estimated to average 1 hour per response, including the tinne tor reviewing instructions, searching existing cata sources. gathering and maintaining the data needed. and completing and reviewing the collection of intormation. Send comments regarding this burden estimate or any other aspect of this collection of intormation, including sugeestions for reducing this burden, to Wastington Headquarters Services, Directorate for Intormation Operations and Reports, 1215 Jefferson Davis Higtwray, Suite 1204. Artington, VA 22202-4302, and to the Office of Management and Budget, Paperwork Reduction Pq0ject (0704-0188), Washington. DC 20503

\begin{tabular}{|l|l|l|}
\hline 1. AGENCY USE ONLY (Leave blank) & $\begin{array}{l}\text { 2. AEPOAT DATE } \\
\text { February 1997 }\end{array}$ & $\begin{array}{l}\text { 3. AEPOAT TYPE AND DATES COVERED } \\
\text { Technical Memorandum }\end{array}$ \\
\hline 4. TIILE AND SUBTTIE & 5. FUNDING NUMBEAS
\end{tabular}

STS-74/Mir Photogrammetric Appendage Structural Dynamics

WU 237-08-02-01

Experiment Preliminary Data Analysis

6. AUTHOA(S)

Michael G. Gilbert Martha E. Demeo

Sharon S. Welch

Richard S. Pappa

7. PERFOAMING ORGANIZATION NAME(S) AND ADDRESS(ES)

8. PERFofMING ORGANIZATION

NASA Langley Research Center

Hampton, VA 23681-0001

REPORT NUMBER

9. SPONSORING / MONTORING AGENCY NAME(S) AND ADDRESS(ES)

National Aeronautics and Space Administration

Washington, DC 20546-0001

10. SPONSORING / MONTORING

AGENCY REPORT NUMBER

NASA TM-110324

11. SUPPLEMENTARY NOTES

To be presented at the 38th AIAA/ASME/ASCE/AHS/ASC Structures, Structural Dynamics, and Materials Conference, April 7-10, 1997, Kissimmee, Florida.

12a. DISTRIBUTION/AVAILABILTTY STATEMENT

Unclassified - Unlimited

Subject Category 39

Availability: NASA CASI, (301) 621-0390

\section{ABSTRACT (Maximum 200 words)}

The Photogrammetric Appendage Structural Dynamics Experiment was designed, developed, and flown to demonstrate and prove measurement of the structural vibration response of a Russian Space Station Mir solar array using photogrammetric methods. The experiment flew on the STS-74 Space Shuttle mission to Mir in November 1995 and obtained video imagery of solar array structural response to various excitation events. The video imagery has been digitized and triangulated to obtain response time history data at discrete points on the solar array. This data has been further processed using the Eigensystem Realization Algorithm modal identification technique to determine the natural vibration frequencies, damping, and mode shapes of the solar array. The results demonstrate that photogrammetric measurement of articulating, non-optically targeted, flexible solar arrays and appendages is a viable, low-cost measurement option for the International Space Station..

Photogrammetric Measurements, Modal Test, Vibration Measurement, Flight Experiment

\begin{tabular}{|c|c|c|}
\hline $\begin{array}{l}\text { 17. SECURATY CLASSIFICATION } \\
\text { OF REPORT }\end{array}$ & $\begin{array}{l}\text { 18. SECUAITY CLASSIFICATION } \\
\text { OF THIS PAGE }\end{array}$ & $\begin{array}{l}\text { 19. SECUATY CLASSIFICATION } \\
\text { OF ABSTRACT }\end{array}$ \\
\hline Unclassified & Unclassified & Unclassified \\
\hline
\end{tabular}

